\title{
DFT Study of Water Adsorption and Decomposition on a Ga-Rich $\mathrm{GaP}(001)(2 \times 4)$ Surface
}

\author{
Seokmin Jeon, ${ }^{\dagger}$ Hyungjun Kim, ${ }^{\ddagger}$ William A. Goddard, III, ${ }^{* \pm, \S}$ and Harry A. Atwater*, ${ }^{\dagger}$ \\ ${ }^{\dagger}$ Thomas J. Watson Laboratories of Applied Physics, California Institute of Technology, MC 128-95, Pasadena, California 91125, \\ United States \\ ${ }^{\ddagger}$ Graduate School of EEWS (WCU), Korea Advanced Institute of Science and Technology (KAIST), Daejeon 305-701, Republic of \\ Korea \\ ${ }^{\S}$ Materials and Process Simulation Center, Beckman Institute, California Institute of Technology, MC 139-74, Pasadena, California \\ 91125, United States
}

\section{Supporting Information}

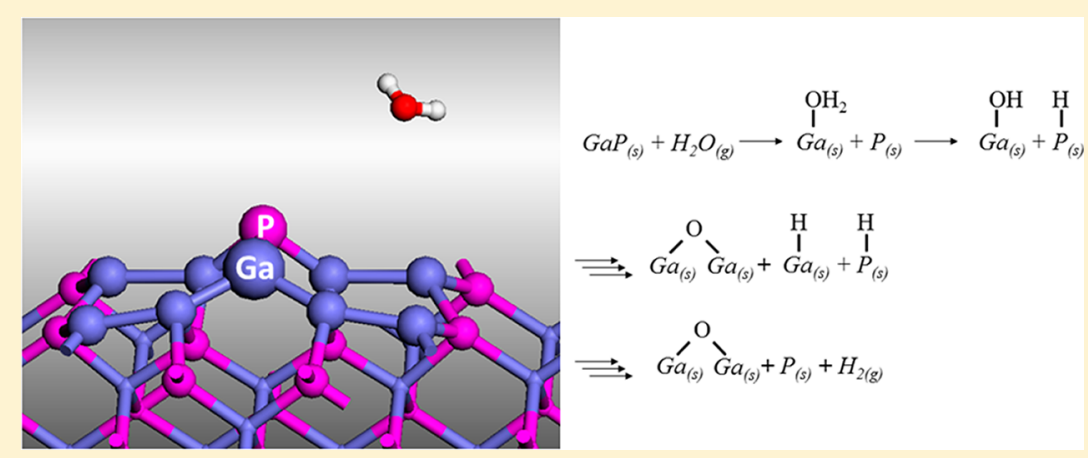

ABSTRACT: We investigate the adsorption and decomposition states of a water molecule on a Ga-rich $\mathrm{GaP}(001)(2 \times 4)$ surface using the PBE flavor of density functional theory (DFT). We selected the $\mathrm{GaP}(001)(2 \times 4)$ mixed dimer surface reconstruction model to represent the Ga-rich $\mathrm{GaP}(001)(2 \times 4)$ surface. Because our focus is on reactions between a single water molecule and the surface, the surface water coverage is kept at $0.125 \mathrm{ML}$, which corresponds to one water molecule in the $(2 \times 4)$ unit cell. We report here the geometries and energies for an exhaustive set of adsorption and decomposition states induced by a water molecule on the $(2 \times 4)$ unit cell. Our results support a mechanism in which (1) the first step is the molecular adsorption, with the water molecule forming a Lewis acid-Lewis base bond to the $\mathrm{sp}^{2} \mathrm{Ga}$ atom of either the first-layer $\mathrm{Ga}-\mathrm{P}$ mixed dimer or the second layer $\mathrm{Ga}-\mathrm{Ga}$ dimers using an addition reaction, (2) which is followed by dissociation of the adsorbed $\mathrm{H}_{2} \mathrm{O}$ to form the $\mathrm{HO} / \mathrm{H}$ decomposition state in which the hydroxyl moiety bonds with surface $\mathrm{sp}^{2} \mathrm{Ga}$ atoms, while the hydrogen moiety binds with the first-layer $\mathrm{P}$ atom, (3) which is followed by the $\mathrm{O} / 2 \mathrm{H}$ decomposition state, in which the oxygen moiety forms bridged $\mathrm{Ga}-\mathrm{O}-$ $\mathrm{Ga}$ structures with surface $\mathrm{Ga}$ dimers while one $\mathrm{H}$ bonds with the first-layer $\mathrm{P}$ atom and the other to surface $\mathrm{sp}^{2} \mathrm{Ga}$ atoms. (4) We find that driving off the hydrogen as $\mathrm{H}_{2}$ leads to the surface oxide state, bridged $\mathrm{Ga}-\mathrm{O}-\mathrm{Ga}$ structures. This surface oxide formation reaction is exothermic relative to the energy of $\mathrm{H}_{2} \mathrm{O}$ plus the reconstructed surface. These results provide guidelines for experiments and theory to validate the key steps and to obtain kinetics data for modeling the growth processes.

\section{INTRODUCTION}

Gallium phosphide ( $\mathrm{GaP}$ ) has several properties that make it an attractive material for electronic, optoelectronic, and electrochemical applications: its electronic properties can be controlled by alloying with other III-V compounds, ${ }^{1-5}$ it can be grown epitaxially on widely used silicon substrates because of a small lattice mismatch, ${ }^{6}$ and it can reduce aqueous $\mathrm{CO}_{2}$ to methanol, which is one of the most challenging but useful species to obtain among various $\mathrm{CO}_{2}$ reduction products in photoelectrochemical (PEC) cells. ${ }^{7-9}$ The oxidation of GaP in the presence of water is a subject of much interest because a number of applications involve liquid or gaseous water. For instance, photoelectrodes of $\mathrm{GaP}$ and $\mathrm{GaInP}$ alloys are operated in aqueous PEC cells to produce $\mathrm{H}_{2}$ or reduce $\mathrm{CO}_{2}$, making them of great interest for renewable energy research. ${ }^{10,11}$ In these PEC cells, it is essential to understand how solvent interactions with semiconductor surfaces affect the oxidation and reduction mechanisms at the semiconductor/electrolyte interfaces. In addition, because water is a common precursor for the atomic layer deposition (ALD) and wet oxidation in semiconductor device fabrication, understanding how surface oxides evolve from water plays an important role in preparing quality oxide layers on the $\mathrm{GaP}$ surface. Accordingly, it is important to determine the adsorption and decomposition

Received: April 30, 2012

Revised: July 3, 2012

Published: July 9, 2012 


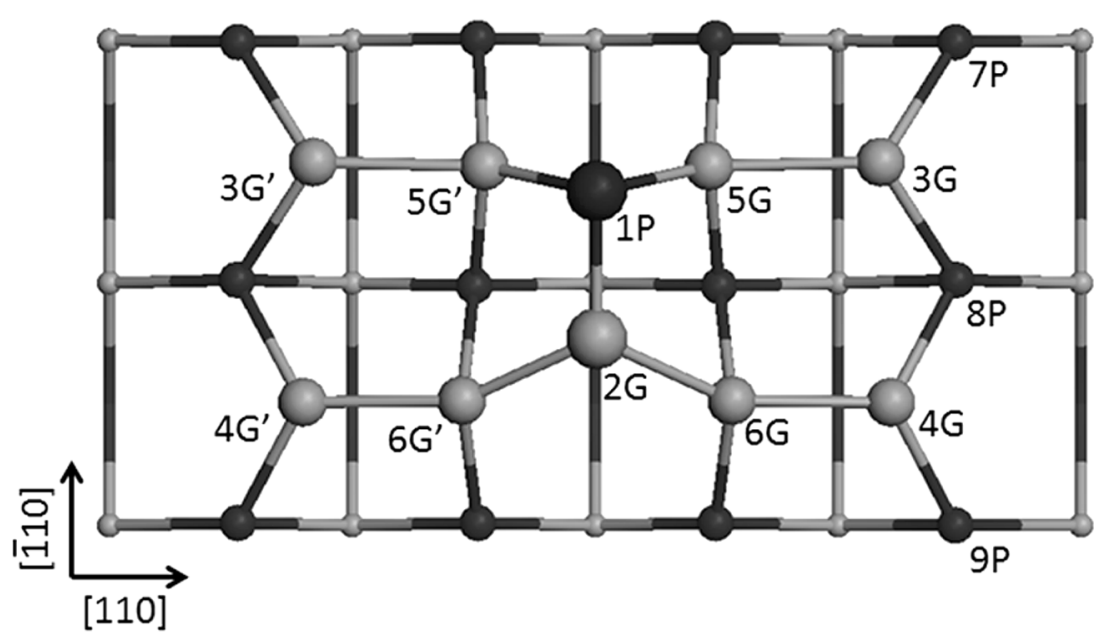

Gallium
Phosphorous

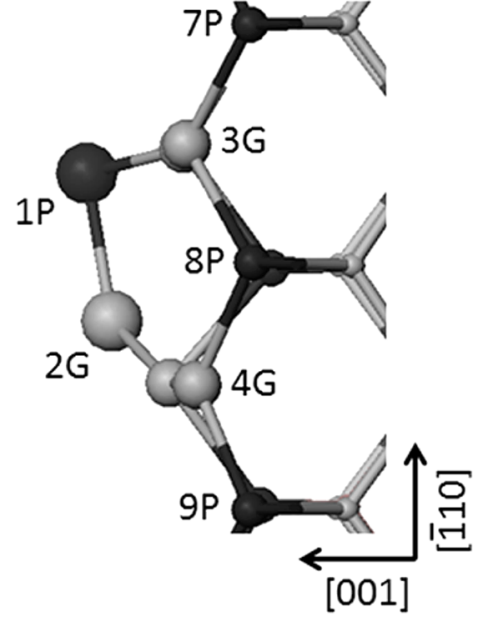

Oxygen

O Hydrogen

Figure 1. Top and side views of the optimized geometry of the bare Ga-rich $\mathrm{GaP}(001)(2 \times 4)$ mixed dimer model. $1 \mathrm{P}$ and $2 \mathrm{G}$ atoms are located on the first layer (topmost layer) with $1 \mathrm{P}$ bonded to $2 \mathrm{G}, 5 \mathrm{G}$, and $5 \mathrm{G}^{\prime}$ atoms and $2 \mathrm{G}$ bonded to $1 \mathrm{P}, 6 \mathrm{G}$, and $6 \mathrm{G}^{\prime}$ atoms. $3 \mathrm{G}, 3 \mathrm{G}^{\prime}, 4 \mathrm{G}$, and $4 \mathrm{G}^{\prime}$ atoms are located on the second layer but each with just two bonds to $\mathrm{P}$ and one bond to $\mathrm{Ga}$. 5G, 5G',6G, and $6 \mathrm{G}^{\prime}$ are located on the second layer with four bonds (three $\mathrm{P}$ atoms and one $\mathrm{Ga}$ atoms for $5 \mathrm{G}$ and $5 \mathrm{G}^{\prime}$; two $\mathrm{P}$ atoms and two $\mathrm{Ga}$ atoms for $6 \mathrm{G}$ and $6 \mathrm{G}^{\prime}$ ). $7 \mathrm{P}, 8 \mathrm{P}$, and $9 \mathrm{P}$ atoms are located on the third layer.

reaction mechanisms from water to an oxide on the GaP surface.

In contrast to the wealth of studies of the adsorption, dissociation, and decomposition of water on the (001) surfaces of elemental semiconductors such as silicon and germanium, ${ }^{12-15}$ there are relatively few studies on any index of surface for the III-V zinc blend semiconductors such as GaAs, $\mathrm{GaP}$, and InP. ${ }^{16-19}$ Although no theoretical studies have been conducted, several experimental results have been reported for the $\mathrm{GaAs}(001)$ surfaces. $^{16-18}$ For example, Massies and Contour have used X-ray photoelectron spectroscopy (XPS) to study the nature of gallium arsenide oxide grown in aqueous solution after a chemical etch. ${ }^{16}$ They suggest that water reacts with both $\mathrm{Ga}$ and As to make gallium hydroxide and arsenious acid $\left(\mathrm{H}_{3} \mathrm{AsO}_{3}\right)$ on the surface. The formation of gallium hydroxide that they suggest agrees with the Webb and Lichtensteiger ultrahigh vacuum (UHV) study ${ }^{17}$ in which it was reported that dissociation results in $\mathrm{HO}-\mathrm{Ga}$ species at room temperature as examined by XPS, ultraviolet photoemission spectroscopy (UPS), and secondary ion mass spectroscopy (SIMS). However, their experiment was conducted on a polycrystalline GaAs surface, thus making their results inconclusive. However, more fundamental and systematic UHV experimental study of water/GaAs(001) was performed by Chung et al. They characterized the thermal behavior of water on a Ga-rich $\mathrm{GaAs}(001)(4 \times 2)$ surface after deposition at $100 \mathrm{~K}$ and during annealing to $750 \mathrm{~K}$ using temperatureprogrammed desorption (TPD), electron energy loss spectroscopy (EELS), and Auger electron spectroscopy (AES). ${ }^{18}$ They observed that molecularly adsorbed water dissociates to produce $\mathrm{HO}-\mathrm{Ga}$ and $\mathrm{H}$-As species between $150 \mathrm{~K}$ and 200 $\mathrm{K}$. In addition, some surface $\mathrm{HO}$ species can be dehydrogenated between $600 \mathrm{~K}$ and $700 \mathrm{~K}$ to produce surface oxides and hydrogen which desorbs. In contrast to the GaAs surfaces, the (110) surface of InP is the only surface on which water adsorption and decomposition mechanisms have been studied. Henrion et al. showed that water is dissociatively adsorbed at low coverage at $100 \mathrm{~K}$, forming HO-In and H-P on the $\operatorname{InP}(110)$ surface. ${ }^{19}$

On the basis of the results on Ga-rich GaAs(001) and $\operatorname{InP}(110),{ }^{16-19}$ one would anticipate water to dissociate and form hydroxide on Ga-rich $\mathrm{GaP}(001)$ and for hydroxide to further dissociate and form oxide. In addition, the $\mathrm{P}$ of the $\mathrm{GaP}(001)$ surface would be involved in the $\mathrm{H}$ dissociation. However, the known stable Ga-rich GaAs(001) surface structure which is the zeta $(4 \times 2)$ model is totally different from the known stable Ga-rich $\mathrm{GaP}(001)$ surface structure which is the $(2 \times 4)$ mixed-dimer model. Therefore, to understand water adsorption and decomposition mechanisms on the $\mathrm{GaP}(001)$ surface, thorough simulation studies using experimentally realistic surface models are needed.

The surface structure of $\mathrm{GaP}(001)$ is complex because of the presence of several surface reconstruction structures. ${ }^{20-24}$ The Ga-rich surface reconstruction structures are especially interesting for two reasons: during the material growth processes, ${ }^{21}$ the desorption rate of $\mathrm{P}$ atoms is higher than that of $\mathrm{Ga}$ atoms under annealing conditions, and during the sputter-annealing process to remove the native oxide, $\mathrm{P}$ desorbs more easily than Ga. ${ }^{25}$ Two likely Ga-rich surface reconstruction structures have been suggested from previous theoretical studies: ${ }^{20-23}$ the $(2 \times 4) \mathrm{Ga}-\mathrm{P}$ mixed dimer structure and the $(2 \times 4) \mathrm{Ga}-\mathrm{Ga}$ dimer structure. Experimental studies, however, argue that the Ga-P mixed dimer is more stable than the GaGa dimer under the commonly attainable Ga-rich conditions. $^{20,21,23,24}$ Thus, we focus on the GaP mixed dimer surface structure.

In this article, we report DFT studies of the adsorption and decomposition of a water molecule on the Ga-rich $\mathrm{GaP}(001)$ $(2 \times 4)$ surface. We consider a molecular coverage of 0.125 monolayer $(\mathrm{ML})$ and optimize the ground-state energy to obtain the structures and energetics for both molecular adsorption and decomposition states. This study helps understanding the thermodynamics for the water-assisted oxidation of $\mathrm{GaP}$ by hydrogen desorption. 
Table 1. Structural Parameters of the Bare Ga-Rich GaP(001)(2×4) Mixed Dimer Models (unit: $\AA$ )

\begin{tabular}{|c|c|c|c|c|c|c|}
\hline method & $\begin{array}{c}\text { lattice } \\
\text { constant }\end{array}$ & $\begin{array}{l}d_{\mathrm{Ga}-\mathrm{P}}^{a} \text { first } \\
\text { layer }\end{array}$ & $\underset{\text { layer }}{\mathrm{Ga}-\mathrm{P} \text { buckling }^{b} \text { first }}$ & $\begin{array}{c}d_{\mathrm{Ga}-\mathrm{Ga}}{ }^{a} \text { second } \\
\text { layer }\end{array}$ & $\begin{array}{c}\mathrm{Ga}-\mathrm{Ga} \text { buckling }^{b} \text { second } \\
\text { layer }\end{array}$ & $\begin{array}{c}\mathrm{P}-\mathrm{P} \text { buckling }^{b} \text { third } \\
\text { layer }\end{array}$ \\
\hline PBE model (this work) & 5.502 & 2.402 & 0.403 & $2.58-2.74$ & 0.431 & 0.337 \\
\hline LDA model (ref 21$)$ & 5.42 & 2.36 & 0.39 & $2.47-2.62$ & & \\
\hline PW91 model (ref 28) & 5.50 & 2.403 & 0.385 & $2.58-2.73$ & 0.43 & 0.31 \\
\hline
\end{tabular}

experiment (ref 26) 5.45

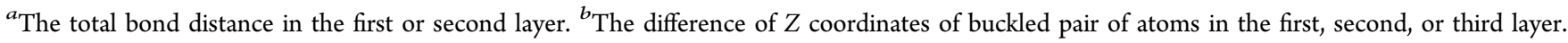

\section{COMPUTATIONAL DETAILS}

We carried out density functional theory (DFT) calculations using the exchange-correlation functional of Perdew-BurkeErnzerhof (PBE). These calculations replaced the Ar core of $\mathrm{Ga}$, the $\mathrm{Ne}$ core of $\mathrm{P}$, and the $\mathrm{He}$ core of $\mathrm{O}$ with projected augmented-wave (PAW) potentials optimized for PBE functionals. Thus $\mathrm{Ga}$ is described with three valence electrons, $\mathrm{P}$ with five, and $\mathrm{O}$ with six. All calculations used the Vienna Abinitio Simulation Package (VASP). The electronic wave functions were expanded in a plane-wave basis set using a cutoff energy of $350 \mathrm{eV}$. The electron density was obtained from four $\mathrm{k}$ points generated by a $4 \times 2 \times 1$ Monkhorst-Pack scheme. The convergence criterion for electronic and ionic optimization were set to $1 \times 10^{-4}$ and $1 \times 10^{-3} \mathrm{eV}$, respectively.

With this description, we calculated a cubic lattice constant of $5.52 \AA$ for bulk GaP (experimental value $5.45 \AA^{26}$ ). Thus, in the slab calculations we used this value for the periodic cell parameters in the $x$ and $y$ directions. All energies are for ground-state structures at $0 \mathrm{~K}$.

The Ga-rich $\mathrm{GaP}(001)(2 \times 4)$ mixed dimer surface was modeled using a periodic slab geometry composed of six Ga and $\mathrm{P}$ layers with a vacuum region equivalent to ten $\mathrm{Ga}$ and $\mathrm{P}$ layers. This cell has $25 \mathrm{Ga}$ and $25 \mathrm{P}$ atoms. The bottom two Ga and $\mathrm{P}$ layers (eight $\mathrm{Ga}$ and eight $\mathrm{P}$ ) were fixed with all remaining atoms fully relaxed. The bottom $\mathrm{P}$ layer was passivated with $0.75 \mathrm{e}^{-}$pseudohydrogen atoms to prevent charge separation, which exerts an artificial electrostatic force. ${ }^{27}$

We calculated the adsorption energies of molecular and decomposed water on the $\mathrm{GaP}(001)(2 \times 4)$. The adsorption energy $E_{\text {ads }}$ is obtained by subtracting the sum of the energies of water and bare $\mathrm{GaP}(001)(2 \times 4)$ from the total energy of wateradsorbed $\mathrm{GaP}(001)(2 \times 4)$ :

$$
\begin{aligned}
E_{\text {ads }}(\mathrm{eV})= & E_{\text {tot }}\left(\mathrm{H}_{2} \mathrm{O} \text { adsorbed on } \mathrm{GaP}\right) \\
& -E(\mathrm{GaP})-E\left(\mathrm{H}_{2} \mathrm{O}\right)
\end{aligned}
$$

To obtain the ground-state energy of a gas-phase water molecule, the water molecule was modeled using a periodic cubic cell with a cell length of $15 \AA$.

\section{RESULTS AND DISCUSSION}

3.1. The Reconstructed GaP(001)(2×4) Surface. A top view of the $\mathrm{GaP}(001)(2 \times 4)$ surface reconstruction model is displayed in Figure 1, with important structure parameters listed and compared with previous studies in Table $1 .^{21,26,28}$ The main structural parameters including dimer lengths and bucklings are in good agreement with other calculation results. The buckling in the table is defined as the difference of the $Z$ coordinates of two atoms consisting of a dimer. Small discrepancies in bond lengths and bucklings may arise from differences in the bulk lattice parameters. Throughout this report, for reader's convenience, the surface $\mathrm{Ga}$ and $\mathrm{P}$ atoms of interest in the $(2 \times 4)$ unit cell are named $1 \mathrm{P}, 2-6 \mathrm{G}, 3-6 \mathrm{G}^{\prime}$, and $7-9 \mathrm{P}$ as shown in Figure 1.

3.2. Premise and Scope of the Simulations. The $(2 \times 4)$ mixed dimer structure has several sites at which a single water molecule might bind, leading to a number of possible adsorption and decomposition states to consider. We consider here four binding states for $\mathrm{H}_{2} \mathrm{O}$, each of which may be involved in several adsorption and dissociation reaction pathways.

(1) Molecular adsorption state: in section 3.3 we consider that a water molecule binds to an empty orbital on the surface Ga. We examined atop, bridge, and hollow sites around the surface $\mathrm{Ga}$ atoms in the $(2 \times 4)$ unit to determine the energetically favorable adsorption geometries for the molecular adsorbate.

(2) $\mathrm{HO} / \mathrm{H}$ decomposition state; in section 3.4 we examine preferred adsorption geometries for the two decomposition adsorbates.

(3) $\mathrm{O} / 2 \mathrm{H}$ decomposition state; in section 3.5 we consider that the $\mathrm{H}$ atom of the $\mathrm{HO}$ adsorbate from the $\mathrm{HO} / \mathrm{H}$ adsorption state could further decompose to create the $\mathrm{O} / 2 \mathrm{H}$ decomposition state.

(4) Surface oxide state $\left(\mathrm{O} / \mathrm{H}_{2}\right.$ state); in section 3.6 we discuss the energetics of the surface oxide states.

In this report, we do not consider the transition states between sequential ground states. Instead, we focus on exploring every possible intermediate state (local minimum) which might be involved in the possible adsorption and decomposition reaction pathways in the $0.125 \mathrm{ML}$ water/ $\mathrm{GaP}(001)(2 \times 4)$ system.

3.3. Molecular Adsorption State. Water molecule with two lone pairs (LP) of electrons can bind as a Lewis base (LB) to the five surface Lewis acid (LA) sites in the $(2 \times 4)$ surface unit cell: $2 \mathrm{G}, 3 \mathrm{G}, 3 \mathrm{G}^{\prime}, 4 \mathrm{G}$, and $4 \mathrm{G}^{\prime}$, each of which makes three covalent bonds to its nearest neighbors, leaving an empty hybrid p-orbital to accept LP electrons of water (Figure 1). We expect no barrier in forming such LA-LB additions. ${ }^{12-15,31-33}$ To obtain accurate adsorption ground-states geometries, we optimized the geometries as follows. Because the $(2 \times 4)$ surface unit cell is symmetric with respect to the mirror plane that includes the [001] and $[-110]$ vectors and bisects the surface unit cell, we considered only sites in the right half of the $(2 \times 4)$ unit cell (Figure 1). We started with 16 initial structures classified into three groups.

(1) Atop structures with the water molecule positioned at the top site: $1 \mathrm{P}, 2 \mathrm{G}, 3 \mathrm{G}, 4 \mathrm{G}, 5 \mathrm{G}$, and $6 \mathrm{G}$ atoms.

(2) Bridge structures with the water molecule positioned at the bridge position of a pair of surface atoms: 1P-2G, 1P5G, 2G-6G, 3G-5G, 4G-6G, 3G-7P, 3G-8P, 4G-8P, and 4G-9P, 
(3) A hollow structure with the water molecule positioned at the center of the trapezoid consisting of $3 \mathrm{G}, 4 \mathrm{G}, 5 \mathrm{G}$, and $6 \mathrm{G}$ atoms.

For all 16 initial structures, a water LP was pointed toward nearby surface Ga atoms. After geometry optimization we found just four distinct local minimum structures from the 16 initial structures as shown in Figure 2 and Table 2.
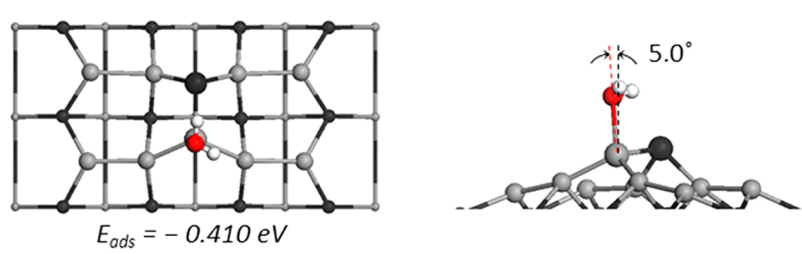

(a) $\mathrm{H} 2 \mathrm{O}-2 \mathrm{G}-\mathrm{SB}$
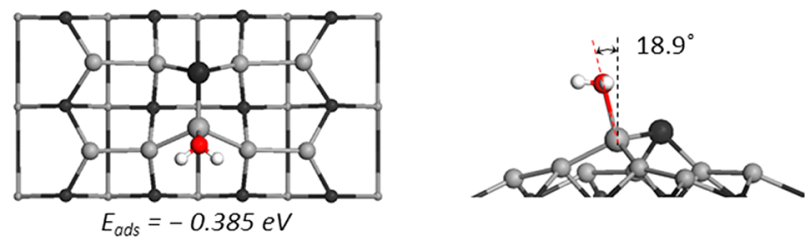

(b) $\mathrm{H} 2 \mathrm{O}-2 \mathrm{G}-\mathrm{WB}$
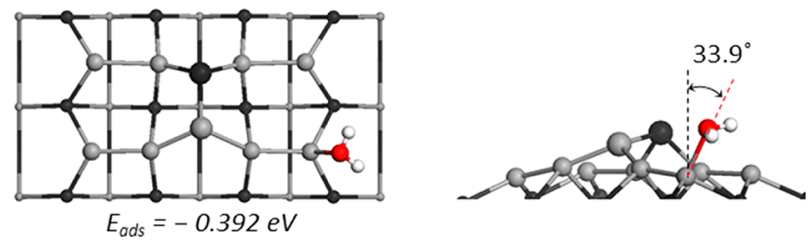

(c) $\mathrm{H} 2 \mathrm{O}-4 \mathrm{G}$
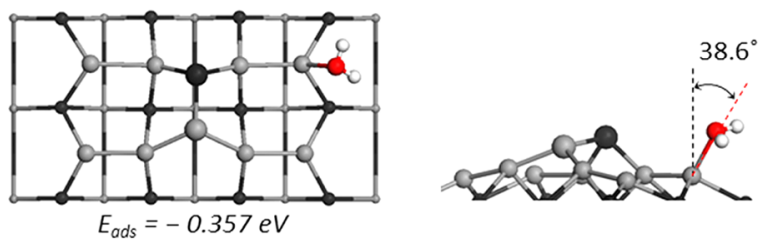

(d) $\mathrm{H} 2 \mathrm{O}-3 \mathrm{G}$

Figure 2. The first column displays optimized geometries (top view) and corresponding adsorption energies of the molecular adsorption states. The second column displays the angles between surface normal (black dashed line) and $\mathrm{O}-\mathrm{Ga}$ bond (red dashed line).

Table 2. Adsorption Energies and Structural Parameters for the Molecular Adsorption States

$\begin{array}{cccccc}\begin{array}{c}\text { adsorption } \\ \text { state }\end{array} & \begin{array}{c}E_{\text {ads }} \\ (\mathrm{eV})\end{array} & \begin{array}{c}d_{\mathrm{Ga}-\mathrm{O}} \\ (\AA)\end{array} & \begin{array}{c}d_{\mathrm{O}-\mathrm{H} 1} \\ (\AA)\end{array} & \begin{array}{c}d_{\mathrm{O}-\mathrm{H} 2} \\ (\AA)\end{array} & \begin{array}{c}\theta_{\mathrm{H}-\mathrm{O}-\mathrm{H}} \\ (\mathrm{deg})\end{array} \\ \text { water }^{a} & & & 0.972 & 0.973 & 104.0 \\ \text { H2O-2G-SB } & -0.410 & 2.308 & 0.976 & 0.983 & 106.4 \\ \text { H2O-2G-WB } & -0.385 & 2.311 & 0.978 & 0.978 & 104.8 \\ \text { H2O-4G } & -0.392 & 2.297 & 0.979 & 0.979 & 105.2 \\ \text { H2O-3G } & -0.357 & 2.345 & 0.979 & 0.980 & 104.6\end{array}$

${ }^{a}$ Values obtained from the current simulation.

The adsorption energies calculated for these four states $(-0.357$ to $-0.410 \mathrm{eV})$ are slightly larger than the adsorption energy in the $\mathrm{H}_{2} \mathrm{O} / \mathrm{Ge}(001)$ system $(-0.33 \mathrm{eV})$ but smaller than those in the $\mathrm{H}_{2} \mathrm{O} / \mathrm{Si}(001)$ system $(-0.51$ to -0.57 $\mathrm{eV}) .{ }^{12-15}$ For the water adsorbed on the $2 \mathrm{G}$ atoms, we found that there are two stable adsorption geometries: a strong bound state (H2O-2G-SB, Figure 2a) and a weak bound state (H2O$2 \mathrm{G}-\mathrm{WB}$, Figure $2 \mathrm{~b}$ ). The adsorption energy for the $\mathrm{H} 2 \mathrm{O}-2 \mathrm{G}-$ $\mathrm{SB}$ state is $0.025 \mathrm{eV}$ greater than that for the $\mathrm{H} 2 \mathrm{O}-2 \mathrm{G}-\mathrm{WB}$ state. More importantly, the two $\mathrm{H}-\mathrm{O}$ bond lengths in the $\mathrm{H} 2 \mathrm{O}-2 \mathrm{G}-\mathrm{SB}$ state differ from each other. The $\mathrm{H}-\mathrm{O}$ bond parallel to $[-110]$ direction is longer than the other by $0.007 \AA$. This occurs because the LP on the $1 \mathrm{P}$ atom interacts with the $\mathrm{H}$ atom of the $\mathrm{H}_{2} \mathrm{O}$ adsorbate, leading to stronger binding. On the other hand, for the molecular adsorption states on the G3 and G4 atoms (Figure 2c,d), the bonding is weak ( -0.357 to $-0.392 \mathrm{eV}$ ), because no neighboring site provides an LP electrons. For the weakly bound states (Figure $2 b-d$ ), the geometry of the $\mathrm{H}_{2} \mathrm{O}$ molecule changes little upon bonding, leading to little change in the water LP, and we consider the bonding to be physisorption. ${ }^{34,35}$ Given the entropy of a free water of $S=45.1 \mathrm{cal} / \mathrm{mol} \cdot \mathrm{K}=1.96 \times 10^{-3} \mathrm{eV} /$ atom $\cdot \mathrm{K},{ }^{36}$ we expect desorption of water for the four molecular adsorption states at $T>\Delta H / \Delta S=209 \mathrm{~K}$. Finally, because the adsorption energies differ by only $0.05 \mathrm{eV}$, we expect them to have similar occupation over the three sites $(2 \mathrm{G}, 3 \mathrm{G}$, and $4 \mathrm{G})$.

3.4. HO/H Decomposition State. We predicted the stable adsorption geometries for the two adsorbates, $\mathrm{HO}$ and $\mathrm{H}$, on the $\mathrm{GaP}(001)(2 \times 4)$.

3.4.1. 1P-2G Site. One can think of the bonding here as adding the proton to the P LP pointed away from the surface to form a covalent $\mathrm{P}-\mathrm{H}$ bond (1.425 $\AA$, Table 3 ), which pulls the

Table 3. Adsorption Energies and Structural Parameters of HO/H Decomposition States

\begin{tabular}{cccccc}
$\begin{array}{c}\text { adsorption } \\
\text { state }\end{array}$ & $E_{\text {ads }}(\mathrm{eV})$ & $\begin{array}{c}d_{\mathrm{Ga}-\mathrm{O}} \\
(\AA)\end{array}$ & $\begin{array}{c}d_{\mathrm{O}-\mathrm{H}} \\
(\AA)\end{array}$ & $\begin{array}{c}d_{\mathrm{P}-\mathrm{H}} \\
(\AA)\end{array}$ & $\theta_{\mathrm{Ga}-\mathrm{O}-\mathrm{H}}(\mathrm{deg})$ \\
HO-3G_H-1P & -0.647 & 1.842 & 0.974 & 1.427 & 109.3 \\
HO-2G_H-1P & -0.637 & 1.838 & 0.976 & 1.425 & 110.9 \\
HO-4G_H-1P & -0.615 & 1.842 & 0.972 & 1.431 & 109.4 \\
\hline
\end{tabular}

covalent $1 \mathrm{P}-2 \mathrm{G}$ bond pair toward the $\mathrm{P}$ (increasing it by 0.140 $\AA$ from $2.419 \AA$ to $2.559 \AA$ ) to form a LA-LB bond while an LP on the $\mathrm{OH}^{-}$binds to what was originally an empty $\mathrm{p}$ orbital on $2 \mathrm{G}$ to form a covalent $\mathrm{Ga}-\mathrm{O}$ bond (1.838 $\AA$, Table 3 ). Thus, we started with the initial position of the $\mathrm{H}$ adsorbate on atop site of the $1 \mathrm{P}$ atom. The mechanism for forming this site might start with the $2 \mathrm{G}$ site of molecularly bound $\mathrm{H}_{2} \mathrm{O}$ (Figure $2 \mathrm{a})$, with the reaction coordinate involving the $\mathrm{H}$ moving toward to $1 \mathrm{P}$ lone pair. This mechanism is compatible with the known decomposition mechanism of water on $\operatorname{GaAs}(110)$ and $\mathrm{GaAs}(001)$ surfaces. ${ }^{29-31}$

3.4.2. $1 P-3 G$ and $1 P-4 G$ Sites. Given the proton bonding to the P LP, we can expect that besides $2 \mathrm{G}$, the $\mathrm{OH}^{-}$binds to the other good sites at the four other sites with Ga empty $p$ orbitals: $3 \mathrm{G}, 4 \mathrm{G}$ and the equivalent $3 \mathrm{G}^{\prime}, 4 \mathrm{G}^{\prime}$. However, we built all 13 initial structures in which the $\mathrm{H}$ is at $1 \mathrm{P}$ while the $\mathrm{HO}$ adsorbate is located at atop site of the 2, 3, and 4G atoms, bridge site of the $1 \mathrm{P}-2 \mathrm{G}, 1 \mathrm{P}-5 \mathrm{G}, 2 \mathrm{G}-6 \mathrm{G}, 3 \mathrm{G}-5 \mathrm{G}, 4 \mathrm{G}-6 \mathrm{G}, 3 \mathrm{G}-$ $7 P$, 3G-8P, 4G-8P, and 4G-9P atoms, and hollow site of the 3G-4G-6G-5G trapezoid. After geometry optimization, of the 13 tested structures, three ground states have the most stable structures: HO-2G_H-1P (considered above), HO-3G_H-1P, and $\mathrm{HO}-4 \mathrm{G} \_\mathrm{H}-1 \mathrm{P}$ shown in Figure 3 with adsorption energies and structural parameters tabulated in Table 3. 


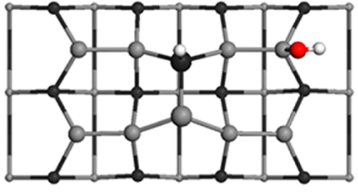

$E_{\text {ads }}=-0.647 \mathrm{eV}$

(a) $\mathrm{HO}-3 \mathrm{G} \_\mathrm{H}-1 \mathrm{P}$

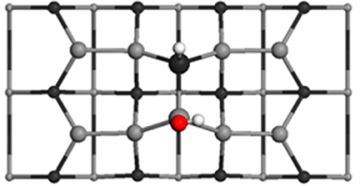

$E_{\text {ads }}=-0.637 \mathrm{eV}$

(b) HO-2G_H-1P

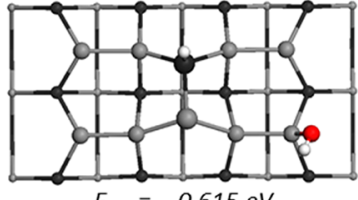

$E_{\text {ods }}=-0.615 \mathrm{eV}$

(c) HO-4G_H-1P

Figure 3. Top view of the optimized geometries of $\mathrm{HO} / \mathrm{H}$ decomposition states.

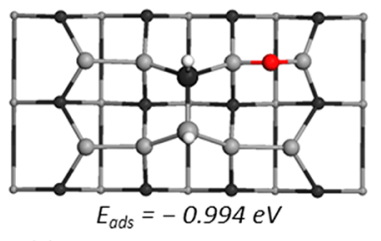

(a) 3G-O-5G_H-1P_H-2G

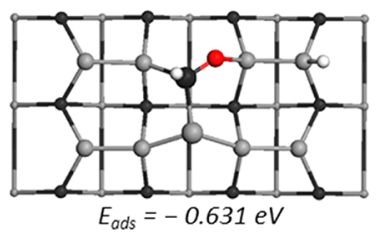

(d) $1 \mathrm{P}-\mathrm{O}-5 \mathrm{G} \mathrm{H}-1 \mathrm{P} \mathrm{H}-3 \mathrm{G}$

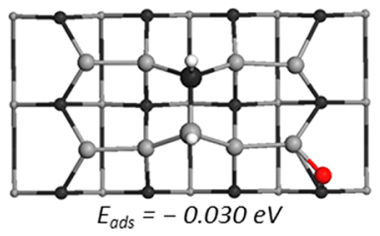

(g) 4G-O-9P H-1P H-2G

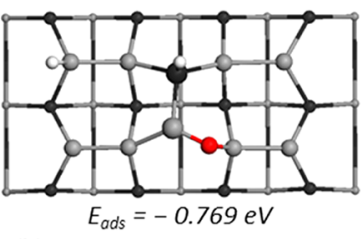

(b) 2G-O-6G_H-1P_H-3G'

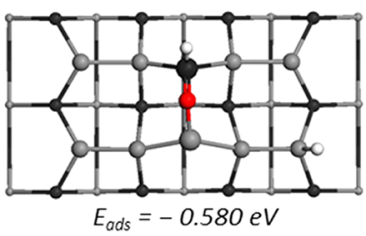

(e) 1P-O-2G_H-1P_H-4G

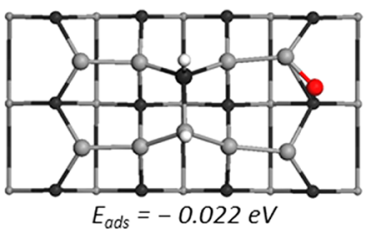

(h) $3 \mathrm{G}-\mathrm{O}-8 \mathrm{P}$ H-1P H-2G

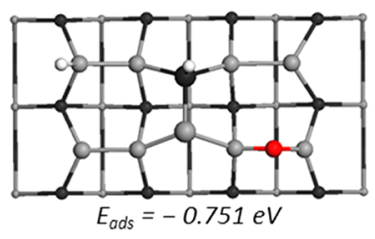

(c) 4G-O-6G_H-1P_H-3G'

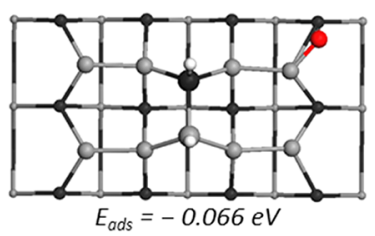

(f) 3G-O-7P_H-1P_H-2G

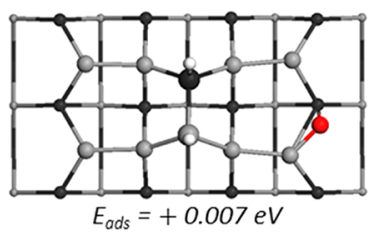

(i) $4 \mathrm{G}-\mathrm{O}-8 \mathrm{P}$ H-1P H-2G

Figure 4. Top view of the optimized geometries of $\mathrm{O} / 2 \mathrm{H}$ decomposition states.

The final chemisorption energies of the three HO-XG H-1P $(X=2,3$, and 4$)$ states are within $5 \%$, but the kinetic barriers to go from water to these states may be significantly different. Thus, we expect that the dissociation mechanism from the $\mathrm{H} 2 \mathrm{O}-2 \mathrm{G}$ state to the HO-2G_H-1P state is preferred, because $\mathrm{H}$ needs to move along by $2-3 \AA$ in migrating from the $\mathrm{O}$ to the P. $\mathrm{H}$ must move by $3-4 \AA$ in the HO-3G_H-1P structure and 5-6 $\AA$ in the HO-4G_H-1P structure, which would lead to a substantial barrier if only one $\mathrm{H}_{2} \mathrm{O}$ were available. In the presence of more water molecules in the unit cell, lower-barrier hydrogen relay mechanisms would likely lead to lower barriers to form HO-3G_H-1P or HO-4G_H-1P. This may require surface water coverage exceeding $0.125 \mathrm{ML}$.

3.5. $\mathrm{O} / 2 \mathrm{H}$ Decomposition State. Next, we investigate complete decomposition of the water adsorbate with one oxygen and two hydrogens, where each reacts at sites on the $\mathrm{GaP}(001)(2 \times 4)$ surface unit cell. To identify stable adsorption geometries for the oxygen adsorbate, we positioned an oxygen atom at several high-symmetry positions (atop, bridge, and hollow sites) of the $(2 \times 4)$ unit cell and carried out geometry optimization. We find that the bridge positions are more favored than the other tested positions for the oxygen adsorption, which agrees well with a previously result. ${ }^{11}$ For the $\mathrm{H}$ adsorbates, the atop positions are stable as we already mentioned in section 3.4.

There is a total of $17 \mathrm{Ga}-\mathrm{Ga}$ or $\mathrm{Ga}-\mathrm{P}$ bridge sites for an oxygen atom to sit on in the $(2 \times 4)$ unit cell, but eight of them are redundant due to the mirror symmetry. Thus, we considered the nine bridge oxide structures: $1 \mathrm{P}-\mathrm{O}-2 \mathrm{G}, 1 \mathrm{P}-\mathrm{O}-$ 5G, 2G-O-6G, 3G-O-5G, 4G-O-6G, 3G-O-7P, 3G-O-8P, 4G$\mathrm{O}-8 \mathrm{P}$, and $4 \mathrm{G}-\mathrm{O}-9 \mathrm{P}$. For each of these nine cases (except for the $1 \mathrm{P}-\mathrm{O}-2 \mathrm{G}$ structure), there are six available atop positions for the $H$. This leads to $6 \times 5 / 2=15$ possible cases for two $H$ to sit on. As discussed in section 3.4, hydrogen prefers to bond with the $1 \mathrm{P}$ atom rather than the Ga; hence, we assumed that one of the hydrogen atoms is located on top of $1 \mathrm{P}(\mathrm{H}-1 \mathrm{P})$, leading to five possibilities for the other hydrogen adsorption sites $\left(\mathrm{H}-\mathrm{XG}\right.$, where $\mathrm{XG}=2 \mathrm{G}, 3 \mathrm{G}, 3 \mathrm{G}^{\prime}, 4 \mathrm{G}$, and $4 \mathrm{G}^{\prime}$ ) per each bridge oxide configuration. The $1 \mathrm{P}-\mathrm{O}-2 \mathrm{G}$ structure, however, has only three different initial structures due to the mirror symmetry. Then, we carried out geometry optimizations for all 43 structures.

Figure S1 in Supporting Information displays the optimized geometries and adsorption energies of the 43 structures. We sorted these 43 into 9 groups; each containing five structures with the same oxygen site and the same first hydrogen site to be atop $1 \mathrm{P}$, but varying the site for the second hydrogen atom to be atop $2 \mathrm{G}, 3 \mathrm{G}, 3 \mathrm{G}^{\prime}, 4 \mathrm{G}$, or $4 \mathrm{G}^{\prime}$ (in the group containing the $1 \mathrm{P}-\mathrm{O}-2 \mathrm{G}$ configuration, there are only three sites for the second $\mathrm{H}$ due to the mirror symmetry: $2 \mathrm{G}, 3 \mathrm{G}$, and $4 \mathrm{G}$ ). We find that within a given group, the adsorption energies of the five different structures vary by just $0.15 \mathrm{eV}$. Of these five structures, one is particularly less stable than the other four. That is, when the second hydrogen atom is bound to the $\mathrm{Ga}$ atom which is a 
Table 4. Adsorption Energies and Structural Parameters of $\mathrm{O} / 2 \mathrm{H}$ Decomposition States

\begin{tabular}{|c|c|c|c|c|c|c|}
\hline adsorption state & $E_{\text {ads }}(\mathrm{eV})$ & $d_{\mathrm{Ga}-\mathrm{O}}(\AA)$ & $d_{\mathrm{A}-\mathrm{O}}^{a}(\AA)$ & $\theta_{\mathrm{Ga}-\mathrm{O}-\mathrm{A}}{ }^{a}(\mathrm{deg})$ & $d_{\mathrm{P}-\mathrm{H}}(\AA)$ & $d_{\mathrm{Ga}-\mathrm{H}}(\AA)$ \\
\hline 3G-O-5G_H-1P_H-2G & -0.994 & 1.791 & 1.871 & 117.4 & 1.427 & 1.570 \\
\hline 2G-O-6G_H-1P_H-3G' & -0.769 & 1.827 & 1.812 & 117.3 & 1.429 & 1.577 \\
\hline 4G-O-6G_H-1P_H-3G' & -0.751 & 1.793 & 1.860 & 119.0 & 1.428 & 1.574 \\
\hline 1P-O-5G_H-1P_H-3G & -0.631 & 1.969 & 1.586 & 128.0 & 1.433 & 1.571 \\
\hline 1P-O-2G_H-1P_H-4G & -0.580 & 1.945 & 1.583 & 130.0 & 1.434 & 1.569 \\
\hline 3G-O-7P_H-1P_H-2G & -0.066 & 1.897 & 1.463 & 110.5 & 1.425 & 1.571 \\
\hline 4G-O-9P_H-1P_H-2G & -0.030 & 1.907 & 1.458 & 109.1 & 1.427 & 1.568 \\
\hline 3G-O-8P_H-1P_H-2G & -0.022 & 1.894 & 1.457 & 109.1 & 1.425 & 1.572 \\
\hline 4G-O-8P_H-1P_H-2G & +0.007 & 1.905 & 1.516 & 111.6 & 1.426 & 1.570 \\
\hline
\end{tabular}

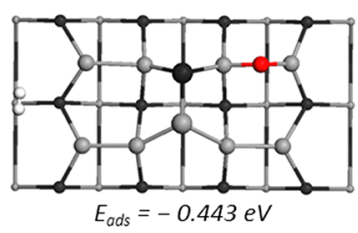

(a) $3 \mathrm{G}-\mathrm{O}-5 \mathrm{G} \mathrm{H} 2$

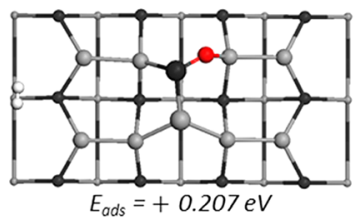

(d) 1P-O-5G_H2

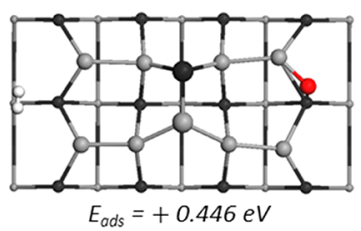

(g) $3 \mathrm{G}-\mathrm{O}-8 \mathrm{P}$

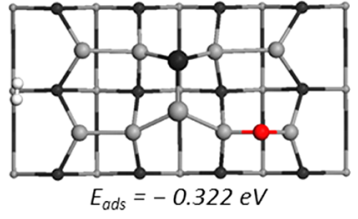

(b) 4G-O-6G_H2

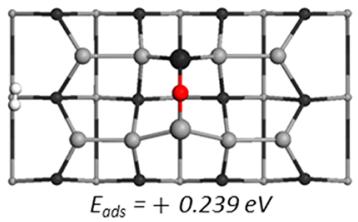

(e) $1 \mathrm{P}-\mathrm{O}-2 \mathrm{G} \_\mathrm{H} 2$

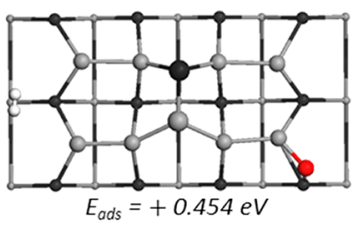

(h) 4G-O-9P_H2

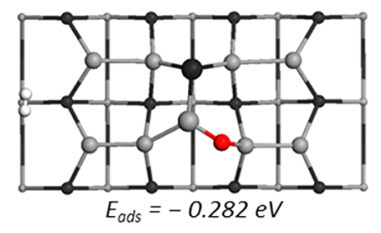

(c) 2G-O-6G_H2

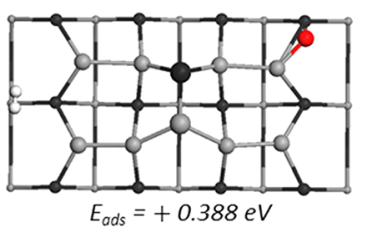

(f) $3 \mathrm{G}-\mathrm{O}-7 \mathrm{P} \_\mathrm{H} 2$

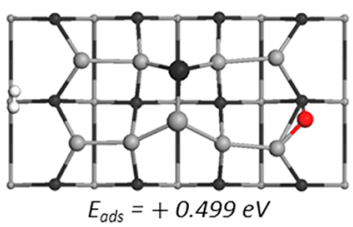

(i) $4 \mathrm{G}-\mathrm{O}-8 \mathrm{P}-\mathrm{H} 2$

Figure 5. Top view of optimized geometries of surface oxide states.

Table 5. Adsorption Energies and Structural Parameters of Surface Oxide States

\begin{tabular}{|c|c|c|c|c|c|c|}
\hline adsorption state & $E_{\mathrm{ads}}(\mathrm{eV})$ & $d_{\mathrm{Ga}-\mathrm{O}}(\AA)$ & $d_{\mathrm{A}-\mathrm{O}}^{a}(\AA)$ & $\theta_{\mathrm{Ga}-\mathrm{O}-\mathrm{A}}{ }^{a}(\mathrm{deg})$ & $d_{\mathrm{H}-\mathrm{H}}(\AA)$ & $d_{\mathrm{H} 2-4 \mathrm{G}}^{b}(\AA)$ \\
\hline 3G-O-5G_H2 & -0.443 & 1.887 & 1.781 & 119.3 & 0.748 & 8.223 \\
\hline 4G-O-6G_H2 & -0.322 & 1.857 & 1.790 & 120.3 & 0.749 & 8.233 \\
\hline 2G-O-6G_H2 & -0.282 & 1.820 & 1.818 & 116.4 & 0.747 & 8.232 \\
\hline 1P-O-5G_H2 & +0.207 & 1.881 & 1.628 & 132.5 & 0.752 & 8.239 \\
\hline 1P-O-2G_H2 & +0.239 & 1.883 & 1.621 & 138.8 & 0.748 & 8.213 \\
\hline 3G-O-7P_H2 & +0.388 & 1.913 & 1.458 & 112.7 & 0.752 & 8.221 \\
\hline 3G-O-8P_H2 & +0.446 & 1.909 & 1.423 & 111.3 & 0.751 & 8.221 \\
\hline 4G-O-9P_H2 & +0.454 & 1.892 & 1.468 & 107.3 & 0.751 & 8.221 \\
\hline 4G-O-8P_H2 & +0.499 & 1.888 & 1.500 & 108.7 & 0.749 & 8.222 \\
\hline
\end{tabular}

${ }^{a} \mathrm{~A}=\mathrm{Ga}$ or P. ${ }^{b}$ Distance between the center of two $\mathrm{H}$ atoms and the nearest $\mathrm{Ga}$ or $\mathrm{P}$ atom located on the surface.

member of a bridge $\mathrm{Ga}-\mathrm{O}-\mathrm{Ga}$ configuration, the adsorption energy is least of the five structures. This is because the Ga$\mathrm{O}-\mathrm{Ga}$ configuration leads to the best energetics of the $\mathrm{O} / 2 \mathrm{H}$ ground states. When a hydrogen atom bonds with one of $\mathrm{Ga}$ atoms of this $\mathrm{Ga}-\mathrm{O}-\mathrm{Ga}$, the bonds around the H-bound $\mathrm{Ga}$ atom change from $\mathrm{sp}^{2}$ to $\mathrm{sp}^{3}$ hybrid character. The significant change of the ideal bond angle $\left(120^{\circ}\right.$ to $\left.109.5^{\circ}\right)$ induced by the change of hybridization builds up geometrical strains around the H-bound $\mathrm{Ga}$ atom, resulting in a smaller adsorption energy. On the other hand, for the other four states, the second hydrogen bonds with an $\mathrm{sp}^{2} \mathrm{Ga}$ atom not involved in the $\mathrm{Ga}-$ $\mathrm{O}-\mathrm{Ga}$. The change in hybridization of the bonds around the $\mathrm{H}$-bound $\mathrm{Ga}$ atoms does not destabilize the adsorption structure as significantly as for the $\mathrm{Ga}-\mathrm{O}-\mathrm{Ga}-\mathrm{H}$ configuration. Figure 4 and Table 4 show the geometries, adsorption energies, and structural parameters of 9 representative ones of the 43 optimized structures. Each representative structure has the most stable adsorption energy among three (in $1 \mathrm{P}-\mathrm{O}-2 \mathrm{G}$ group) or five (in eight other groups) structures in each group. 


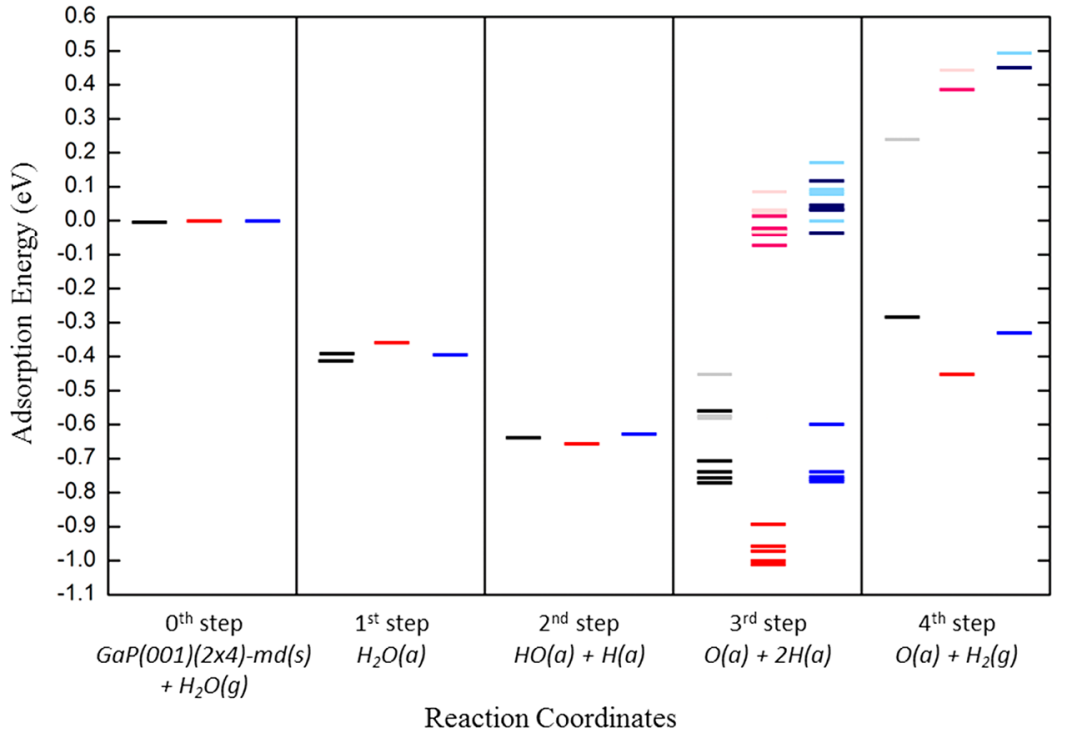

Figure 6. Adsorption energies versus reaction coordinates of entire adsorption states (details in section $\mathrm{S} 3$ of Supporting Information). Black lines indicate the mechanism for H2O-2G-WB, H2O-2G-SB $\rightarrow$ HO-2G_H-1P $\rightarrow$ 2G-O-6G_H-1P_H-XG $\rightarrow$ 2G-O-6G_H2 (XG $=2 \mathrm{G}, 3 \mathrm{G}, 3 \mathrm{G}^{\prime}, 4 \mathrm{G}$, and $\left.4 \mathrm{G}^{\prime}\right)$. In the third and fourth steps, we use gray for $1 \mathrm{P}-\mathrm{O}-2 \mathrm{G} \_\mathrm{H}-1 \overline{\mathrm{P}} \mathrm{H}-\mathrm{XG}$ and $1 \mathrm{P}-\mathrm{O}-\overline{2} \mathrm{G} \_\mathrm{H} 2$ states. Red lines indicate the mechanism for $\mathrm{H} 2 \mathrm{O}-3 \mathrm{G}$ $\rightarrow$ HO-3G_H-1P $\rightarrow$ 3G-O-5G_H-1P_H-XG $\rightarrow$ 3G-O-5G_ $\bar{H} 2\left(X \bar{G}=2 G, 3 G, 3 G^{\prime}, 4 G\right.$, and $\left.4 G^{\prime}\right)$. In the third and fourth steps, we use dark red for 3G-O-7P_- $\bar{H}-1 \mathrm{P} \_\mathrm{H}-\mathrm{XG}$ and 3Ga-O-7P_H2 states, and light red for 3G-O-8P_H-1P_H-XG and 3G-O-8P_H2 states. Blue lines indicate the mechanism for $\overline{\mathrm{H}} 2 \mathrm{O}-4 \mathrm{G} \rightarrow \mathrm{HO}-4 \mathrm{G} \mathrm{H}-\overline{\mathrm{P}} \rightarrow 4 \mathrm{G}-\mathrm{O}-6 \mathrm{G} H-1 \mathrm{P} H-\mathrm{XG} \rightarrow 4 \mathrm{G}-\mathrm{O}-\overline{6 G} \mathrm{H} 2 \overline{(X G}=2 \mathrm{G}, 3 \mathrm{G}, 3 \mathrm{G}^{\prime}, 4 \overline{\mathrm{G}}$, and $\left.4 \mathrm{G}^{\prime}\right)$. In the third and fourth steps, we use dark blue for 4G-O-9P_H-1P_H-XG and 4G-O-9P_H2 states, and light blue for 4G-O-8P_H-1P_H-XG and 4G-O-8P_H2 states.

3.6. Surface Oxide State $\left(\mathrm{O} / \mathrm{H}_{2}\right.$ state). The remaining adsorption state for water adsorption and decomposition reactions is the surface oxide state with both $\mathrm{H}$ adsorbates leaving as an $\mathrm{H}_{2}$ molecule. Surface oxide formation after desorption of $\mathrm{H}_{2}$ has been observed experimentally in temperature-programmed desorption (TPD) experiments on water/GaAs(001). ${ }^{18,29}$ Sloan et al. observed the $D_{2}$ TPD peak at $400-600 \mathrm{~K}$ from the $\mathrm{GaAs}(100)$ surface which had been covered with $\mathrm{D}_{2} \mathrm{O}$ dissociative adsorbates. ${ }^{29}$ Chung et al. also obtained the $\mathrm{D}_{2}$ desorption spectrum at $600-700 \mathrm{~K}$ from the $\mathrm{D}_{2} \mathrm{O}$-adsorbed $\mathrm{GaAs}(001)(4 \times 2)$ surface. ${ }^{18}$ They suggested a $\mathrm{D}_{2}$ regeneration mechanism in which the $\mathrm{D}_{2}$ gas is produced from two hydroxyl adsorbates when the surface is annealed. To provide insights about the energetics of this mechanism while keeping the simulation cell size (surface water coverage of $0.125 \mathrm{ML}$ ) fixed, we calculated the final ground states where the oxide is left on the $\mathrm{GaP}$ surface after the desorption of $\mathrm{a} \mathrm{H}_{2}$ molecule.

We built the initial structures for the oxygen adsorbates whose coordinates referred to those of the oxygen adsorbates in the optimized structures of the $\mathrm{O} / 2 \mathrm{H}$ state in section 3.5 . Figure 5 and Table 5 show the final structures and their energies in the surface oxide state. The two hydrogen atoms in the surface oxide state are combined to a hydrogen molecule in the vacuum. Because we want to describe a desorbed hydrogen molecule, we selected the initial coordinates of the hydrogen molecule to be as far as possible from either top or bottom surface. During the geometry optimization, the coordinates of the hydrogen atoms in vacuum are fully relaxed, but the coordinates of the hydrogen molecule remain little changed in the final structures (less than $0.1 \%$ ), implying negligible interactions between the hydrogen molecule and the two surfaces. To verify that the presence of an $\mathrm{H}_{2}$ in the vacuum of the simulation unit cell does not affect energetics of the surface oxide, we compared the coordinates of the surface atoms and the adsorption energies for the surface oxide structure with and without a hydrogen molecule in vacuum (Figure S2 in Supporting Information). For all simulated oxide structures, differences of the coordinates of surface atoms and the adsorption energies for the two structures are less than $2 \%$ and $0.4 \%$, respectively. More importantly, there was no correlation between the variation on the hydrogen-to-surface distance and the variation on the adsorption energy. That is, the small energy difference (0.4\%) might arise only from slight differences in the convergence levels in the structures during the geometry optimization. Therefore, our $\mathrm{O} / \mathrm{H}_{2}$ state models are appropriately constructed to represent the surface oxide state where hydrogen adsorbates are completely desorbed from the surface.

From the simulation results of the surface oxide state summarized in Table 5, we conclude that thermodynamically stable oxide structures after the hydrogen molecule is desorbed are $\mathrm{Ga}-\mathrm{O}-\mathrm{Ga}$ surface bridge structures. The net enthalpy changes for forming the surface $\mathrm{Ga}-\mathrm{O}-\mathrm{Ga}$ bridge oxides are negative (thermodynamically favored) compared to the reference state of water plus clean $\mathrm{GaP}$ surface. In contrast, the surface oxide states involving the $\mathrm{Ga}-\mathrm{O}-\mathrm{P}$ bridge structures are less stable than this reference.

3.7. Overall Reaction Mechanism. The previous sections explored all ground states potentially involved in the adsorption and decomposition mechanisms of a single water on the Garich $\mathrm{GaP}(001)(2 \times 4)$ mixed-dimer surface. Although we did not calculate the transition states for the reactions forming these states from $\mathrm{H}_{2} \mathrm{O}$, we suggest some possible reaction pathways in this section. Figure 6 indicates the adsorption energies of all the ground states introduced above. Ground states with the same color indicate adsorption species that we assume are involved in the same reaction pathway. For instance, the black lines along the reaction coordinates indicate the ground states in the decomposition mechanism of the water molecule adsorbed on the $2 \mathrm{G}$ site. 
All three adsorption pathways are exothermic from the zeroth step to the first step. In the first step, the energy variations for the three adsorption states $\left(\mathrm{H}_{2} \mathrm{O}-2,3\right.$, and $\left.4 \mathrm{G}\right)$ are small. Similarly, the $\mathrm{H}$ decomposition reactions from the first step to the second step are exothermic for all three cases. In addition, because the three $\mathrm{HO}$ decomposition states have comparable adsorption energies, there is no preference over the three decomposition pathways in terms of thermodynamics. However, considering kinetics of the decomposition reactions (first step to second step), we anticipate that the HO-2G_H-1P state is favored, because the $\mathrm{H}$ transportation distance, which is related with barrier height, is much shorter than for the other structures.

In the third step, noticeable differences are observed for the adsorption energies of eight surface bridge oxide groups (black, gray, red, light red, dark red, blue, light blue, and dark blue).

- First, $\mathrm{Ga}-\mathrm{O}-\mathrm{Ga}$ bridge oxide configurations are more stable than $\mathrm{Ga}-\mathrm{O}-\mathrm{P}$ bridge oxide configurations.

- Second, the bridge oxides consisting of second-layer Ga atoms and third-layer $\mathrm{P}$ atoms (light red, dark red, light blue, and dark blue) are very unstable whose adsorption energies are larger than the zeroth step energy, $0 \mathrm{eV}$.

- Third, compared with the energies of three groups of $\mathrm{Ga}-\mathrm{O}-\mathrm{Ga}$ bridge oxides such as $2 \mathrm{G}-\mathrm{O}-6 \mathrm{G} \_\mathrm{H}-1 \mathrm{P} \_\mathrm{H}-$ $\mathrm{XG}$ (black) $\left(\mathrm{XG}=2 \mathrm{G}, 3 \mathrm{G}, 3 \mathrm{G}^{\prime}, 4 \mathrm{G}\right.$ and $\left.4 \overline{\mathrm{G}^{\prime}}\right), 3 \overline{\mathrm{G}-\mathrm{O}-}$ 5G_H-1P_H-XG (red), and 4G-O-6G_H-1P_H-XG (blue), the 3G-O-5G_H-1P_H-XG group is the most stable.

The three decomposition pathways connecting the black, red, and blue lines from the second step to the third step are thermodynamically favorable. Of the three pathways, the pathway to form the 3G-O-5G configuration is the most favorable. However, because we have not verified the transportation mechanism of the second hydrogen atom from the $\mathrm{HO}$ configuration to the $\mathrm{H}-\mathrm{Ga}$ configuration, we cannot conclude which pathway is preferred.

In the fourth step, after desorption of hydrogen adsorbates, we suggest the $\mathrm{Ga}-\mathrm{O}-\mathrm{Ga}$ bridged oxide to be the most stable adsorption configuration. The adsorption energy for the bridge oxide state is lower than initial state. Thus, decomposition of water to form surface oxide on the Ga-rich $\mathrm{GaP}(001)(2 \times 4)$ mixed dimer surface is thermodynamically favorable.

Reference 18 suggests that surface oxides are formed after regeneration and desorption of water or hydrogen gases from two $\mathrm{HO}$ adsorbates rather than from two hydrogen adsorbates.

$$
\begin{aligned}
& 2 \mathrm{Ga}-\mathrm{OD} \rightarrow \mathrm{D}_{2}(\mathrm{~g})+2 \mathrm{GaO} \\
& 2 \mathrm{Ga}-\mathrm{OD} \rightarrow \mathrm{GaO}+\mathrm{D}_{2} \mathrm{O}(\mathrm{g})+\mathrm{Ga}
\end{aligned}
$$

This hydrogen regeneration was verified using TPD, HREELS, and XPS experiments. Because we restricted ourselves to one $\mathrm{H}_{2} \mathrm{O}$ per cell, we could not examine this mechanism, which we consider as reasonable. However we do describe the final $\mathrm{GaO}$ formed.

Foord et al. ${ }^{37}$ observed regeneration of hydrogen gas from hydrogen adsorbates on the GaAs(100) surface and suggested a hydrogen regeneration mechanism in the $\mathrm{H}_{2} \mathrm{~S} / \mathrm{GaAs}(100)$ system which proceeds through

$$
2 \mathrm{H}(\mathrm{ads}) \rightarrow \mathrm{H}_{2}(\mathrm{~g})
$$

It seems to us that an intermediate mechanism in which a weaker surface $\mathrm{H}$ starts to break and then forms $\mathrm{H}_{2}$ from an adjacent $\mathrm{OH}$ might be reasonable. However, this last step of $\mathrm{H}_{2}$ formation will require detailed reaction pathways starting with the species we have enumerated.

3.8. Caveats. In this report, we discuss extensively the thermodynamics of all possible stable ground states, but we do not suggest full decomposition and desorption mechanisms to clarify how surface oxide and gaseous hydrogen are formed from $\mathrm{HO}$ and $\mathrm{H}$ adsorbates. Therefore, one should use care when interpreting the reaction pathways in Figure 6, especially, the pathways from the second step to the fourth step.

Because the pathways do not include transition state energies, there could be additional barriers and local minima between neighboring ground states. In addition, we have kept the water coverage at $0.125 \mathrm{ML}$ for each $(2 \times 4)$ unit cell. However, it could be that some cells would locally have more than one water molecule even though the average coverage is $0.125 \mathrm{ML}$. For instance, there might be two neighboring $\mathrm{HO}$ adsorbates in one $(2 \times 4)$ unit cell, which could lead to a lower barrier pathway to produce the final surface oxide state similarly as observed in the water/Ga-rich $\mathrm{GaAs}(001)(2 \times 4)$ system. ${ }^{16}$

\section{CONCLUSION}

We report here the adsorption and decomposition thermodynamics of $0.125 \mathrm{ML}$ water on a Ga-rich $\mathrm{GaP}(001)(2 \times 4)$ surface predicted using ab initio DFT simulation. This surface reconstruction is complicated, leading to a number of potential decomposition reaction pathways. This study is the first to exhaustively consider the various possible reaction intermediates involved in mechanisms of water-induced transformations on $\mathrm{GaP}(001)(2 \times 4)$. Here we explored all reasonable ground states involved in most possible adsorption and decomposition pathways, but we have not provided a full reaction mechanism which would require searching transition states and quantifying barrier heights.

We consider a sequence of the ground states involving four adsorption states:

- The molecular water adsorption state, where we find that the molecular adsorption geometry is most stable when $\mathrm{H}_{2} \mathrm{O}$ is adsorbed on top of the surface $\mathrm{sp}^{2} \mathrm{Ga}$ atom of either $\mathrm{Ga}-\mathrm{P}$ mixed dimer or $\mathrm{Ga}-\mathrm{Ga}$ dimers.

- The $\mathrm{HO} / \mathrm{H}$ decomposition state, where we find that the $\mathrm{HO}$ group bonds with a surface $\mathrm{sp}^{2} \mathrm{Ga}$ atom, and $\mathrm{H}$ binds with the first-layer $\mathrm{P}$ atom, with both $\mathrm{HO}$ and $\mathrm{H}$ groups having the atop configurations.

- The $\mathrm{O} / 2 \mathrm{H}$ decomposition state, where the thermodynamically favorable adsorption structure for the $\mathrm{O}$ atom is the bridged $\mathrm{Ga}-\mathrm{O}-\mathrm{Ga}$ structure. Here the one hydrogen adsorbate prefers to be located on top of the first-layer $\mathrm{P}$ atom while the other on a surface $\mathrm{sp}^{2} \mathrm{Ga}$ atom.

- The surface oxide state, where the $\mathrm{O}$ atom forms the $\mathrm{Ga}-\mathrm{O}-\mathrm{Ga}$ bridge oxide configuration after desorption of $\mathrm{H}_{2}$. The oxide formation process is exothermic when referenced to the initial state energy.

\section{ASSOCIATED CONTENT}

\section{S Supporting Information}

Structures and adsorption energies of all $43 \mathrm{O} / 2 \mathrm{H}$ states. Comparison of geometric parameters and adsorption energies of the surface oxide states with and without a hydrogen molecule in vacuum. Detailed explanation in Figure 6. This 
material is available free of charge via the Internet at http:// pubs.acs.org.

\section{AUTHOR INFORMATION}

\section{Corresponding Author}

*E-mail: wag@wag.caltech.edu (W.A.G.); haa@caltech.edu (H.A.A.).

\section{Notes}

The authors declare no competing financial interest.

\section{ACKNOWLEDGMENTS}

This work was supported by DARPA and the Joint Center for Artificial Photosynthesis (JCAP), a project of the Office of Basic Energy Sciences, US Department of Energy. S. Jeon thanks the Kwanjeong Educational Foundation for support. $\mathrm{H}$. Kim and W. A. Goddard acknowledge support from the WCU (World Class University) program through the National Research Foundation of Korea funded by the Ministry of Education, Science and Technology (R31-2008-000-10055-0).

\section{REFERENCES}

(1) Khaselev, O.; Turner, J. A. Science 1998, 280, 425-427.

(2) Khaselev, O.; Turner, J. A. J. Electrochem. Soc. 1998, 145, 33353339

(3) King, R. R.; Law, D. C.; Edmondson, K. M.; Fetzer, C. M.; Kinsey, G. S. Appl. Phys. Lett. 2007, 90, 183516.

(4) Geisz, J. F.; Friedman, D. J.; Ward, J. S.; Duda, A.; Olavarria, W. J. Appl. Phys. Lett. 2008, 93, 123505.

(5) Guter, W.; Schöne, J.; Philipps, S. P.; Steiner, M.; Siefer, G. Appl. Phys. Lett. 2009, 94, 223504

(6) Tamboli, A. C.; Malhotra, M.; Kimball, G. M.; Turner-Evans, D. B.; Atwater, H. A. Appl. Phys. Lett. 2010, 97, 221914.

(7) Barton, E. E.; Rampulla, D. M.; Bocarsly, A. B. J. Am. Chem. Soc. 2008, 130, 6342-6344.

(8) Aurian-Blajeni, B.; Halmann, M.; Manassen, J. Sol. Energy Mater. 1983, 8, 425-440.

(9) Halmann, M. Nature 1978, 275, 115-116.

(10) Tomkiewicz, M.; Woodall, J. M. Science 1977, 196, 990-991.

(11) Wood, B. C.; Ogitsu, T.; Schwegler. J. Photon. Energy 2011, 1, 016002.

(12) Warschkow, O.; Schofield, S. R.; Marks, N. A.; Randy, M. W.; Smith, P. V.; McKenzie, D. R. Phys. Rev. B 2008, 77, 201305(R).

(13) Cho, J.-H.; Kim, K. S. Phys. Rev. B 2000, 61, 4503.

(14) Foraker, A.; Doren, D. J. J. Phys. Chem. B 2003, 107, 85078510.

(15) Cho, J.-H.; Jin, K.; Kim, K. S. Phys. Rev. B 2002, 66, 113306.

(16) Massies, J.; Contour, J. P. Appl. Phys. Lett. 1985, 46, 1150.

(17) Webb, C.; Lichtensteiger, M. J. Vac. Sci. Technol. 1982, 21, 659.

(18) Chung, C.-H.; Yi, S. I.; Weinberg, W. H. J. Vac. Sci. Technol., A 1998, 16, 1785-1789.

(19) Henrion, O.; Klein, A.; Jaegermann, W. Surf. Sci. 2000, 457, L337.

(20) Frisch, A. M.; Schmidt, W. G.; Bernholc, J.; Pristovsek, M.; Esser, N.; Richter, W. Phys. Rev. B 1999, 60, 2488.

(21) Lüdge, K.; Vogt, P.; Pulci, O.; Esser, N.; Bechstedt, F.; Richter, W. Phys. Rev. B 2000, 62, 11046.

(22) Schmidt, W. G.; Bernholc, J.; Bechstedt, F. Appl. Surf. Sci. 2000, $166,179-184$.

(23) Schmidt, W. G. Appl. Phys. A: Mater. Sci. Process. 2002, 75, 8999.

(24) Sanada, N. Surf. Sci. 1999, 419, 120-127.

(25) Naitoh, M.; Watanabe, A.; Konish, A.; Nishigaki, S. Jpn. J. Appl. Phys. 1996, 35, 4789-4790.

(26) Numerical Data and Functional Relationships in Science and Technology; Landolt-Börnstein Group III; Hellwege, K.-H.; Madelung, O., Eds.; Springer-Verlag: Berlin, 1982; Vols. 17, 22.
(27) Shiraishi, K. J. Phys. Soc. Jpn. 2006, 59, 3455-3458.

(28) Li, D. F.; Liu, K. Z.; Ziao, H. Y.; Dong, H. N.; Zu, X. T. J Alloy. Compd. 2007, 440, 229-235.

(29) Sloan, D. W.; Sun, Y.-M.; White, J. M. J. Vac. Sci. Technol., A 1996, 14, 216-222.

(30) Henrion, O.; Löher, T.; Klein, A.; Pettenkofer, C.; Jaegermann, W. Surf. Sci. 1996, 366, L685-L688.

(31) Voznyy, O.; Dubowski, J. J. J. Phys. Chem. C 2008, 112, 37263733.

(32) Tang, S.; Cao, Z. J. Phys. Chem. A. 2009, 113, 5685-5690.

(33) Lu, H.-L.; Chen, W.; Ding, S.-J.; Zhang, D. W.; Wang, L.-K. Chem. Phys. Lett. 2007, 445, 188-192.

(34) Kolasinski, K. Surface Science. Foundation of Catalysis and Nanoscience; John Wiley \& Sons Ltd: Hoboken, NJ, 2002; p 86.

(35) McCash, E. M. Surface Chemistry; Oxford Univ. Press: Cary, NC, 2001; p 62.

(36) Standard Thermodynamic Properties of Chemical Substances. CRC Handbook of Chemistry and Physics, 92nd ed.; Internet Version 2012; Haynes, W. M., Ed.; CRC Press/Taylor and Francis: Boca Raton, 2012; p 5.

(37) Foord, J. S.; FitzGerald, E. T. Surf. Sci. 1994, 306, 29-36.

(38) Skutin, E. D. Tech. Phys. 2009, 54, 704-711. 